\title{
Desafios da Educação Especial infantil em Angola
}

\author{
Teresa Patatas \& Isabel Sanches
}

\begin{abstract}
Resumo
Este artigo tem como objetivo descrever, para compreender, a realidade da Educação Especial em Angola, especificando o caso do Namibe. Para o seu cumprimento foi feita uma pesquisa bibliográfica que, devido à escassez de fontes, foi complementada com pesquisa e análise documentais. Foi, ainda, realizada uma entrevista semiestruturada à diretora pedagógica da Escola Especial do Namibe. A informação recolhida nos documentos disponibilizados, bem como na entrevista, foi sujeita a uma análise de conteúdo, tendo sido agregada em unidades temáticas, o que nos permitiu dar uma panorâmica sobre o atendimento às crianças e jovens com necessidades educativas especiais (NEE), em Angola e mais especificamente em Namibe. Verifica-se uma vontade de vencer este desafio, por parte dos profissionais e, também, das políticas, embora ainda haja um longo caminho a percorrer.
\end{abstract}

Palavras-chave:

educação especial; necessidades educativas especiais; Angola; Namibe. 


\section{Challenges of special education for children in Angola}

Abstract: This article aims to describe and understand the reality of Special Education in Angola, particularly in Namibe. For this purpose, bibliographic research was done. Due to the scarcity of sources, it was complemented by documentary research and analysis. Additionally, a semi-structured interview was conducted with the Director of Education of Escola Especial do Namibe. A content analysis was conducted, focusing on thematic units. This provided an overview of the care of children and young people with Special Educational Needs (SEN), which includes the efforts of both professionals and policies to overcome this challenge, despite still having a long way to go.

Keywords: special éducation; special educational needs; Angola; Namibe.

\section{Les défis de l'éducation spéciale pour les enfants en Angola}

Résumé : Cet article vise à décrire, pour comprendre, la réalité de l'éducation spéciale en Angola, en précisant le cas de Namibe. Pour son accomplissement, une recherche bibliographique a été faite qui, en raison de la rareté des sources, a été complétée par des analyses documentaires. Une interview semi-structurée a également été réalisée avec le directeur pédagogique de l'école spéciale à Namibe. Les informations rassemblées dans les documents mis à disposition, ainsi que dans l'interview, ont fait l'objet d'une analyse de contenu et ont été regroupées en unités thématiques, ce qui nous a permis de montrer la prise en charge des enfants et des jeunes ayant des besoins éducatifs particuliers, en Angola et plus particulièrement à Namibe. II existe une volonté de relever ce défi, à la fois par les professionnels et par les politiques, même s'il reste encore beaucoup de chemin à parcourir. Mots-clés: éducation spécialisée, besoins éducatifs spéciaux; Angola; Namibe.

\section{Desafíos de la educación especial infantil en Angola}

Resumen: Este artículo tiene como objetivo describir, para comprender, la realidad de la Educación Especial en Angola, especificando el caso de Namibe. Para su cumplimiento se hizo una investigación bibliográfica que, debido a la escasez de fuentes, fue complementada con investigación y análisis documentales. Se realizó una entrevista semiestructurada a la directora pedagógica de la Escuela Especial de Namibe. La información recogida en los documentos disponibles, así como en la entrevista, fue sujeta a un análisis de contenido, habiendo sido agregada en unidades temáticas, lo que nos permitió dar una panorámica sobre la atención a los niños y jóvenes con necesidades educativas especiales (NEE), en Angola y más específicamente en Namibe. Se observa una voluntad de vencer este desafío, por parte de los profesionales y, también, de las políticas, aunque todavía hay un largo camino por recorrer. Palabras clave: educación especial, necesidades educativas especiales; Angola; Nambe. 


\section{Introdução}

Em Angola ser criança não é fácil. Apesar da paz, vive-se numa sociedade ainda marcada e dilacerada pela guerra, por deslocações populacionais, pela crise económica e pela pobreza que atinge a maioria dos habitantes. Ser criança com alguma deficiência é ainda mais desafiante, pois tem de enfrentar preconceitos culturais, estigmas, rótulos e limitações em todo o tipo de recursos e acesso a serviços de apoio necessários à sua integração social e inclusão escolar. Embora haja uma evolução no modo social de ver a criança com necessidades especiais, há ainda mitos e algumas crenças religiosas, mais evidentes nas zonas suburbanas e rurais, que conduzem ao preconceito, violência, discriminação, negligência, exploração, marginalização ou exclusão da criança e até mesmo das suas famílias. Os dados estatísticos nessa área são escassos e muitos casos não são notificados.

Numa sociedade inclusiva, que se deseja construir em Angola, a diferença entre pessoas não pode ser obstáculo para a igualdade de direitos à educação. Um ano após ser acolhida pela Assembleia Geral das Nações Unidas, Angola aderiu à Convenção sobre os Direitos da Criança ${ }^{1}$ (1990). A educação formal tornou-se um dos direitos universais da criança. Apesar dos esforços governamentais, este direito ainda não é exercido para muitas crianças, especialmente para aquelas que se encontram em situação de deficiência. A modalidade de Educação Especial ${ }^{2}$ surge como resposta educativa para os cidadãos com Necessidades Educativas Especiais (NEE).

De acordo com o diretor do INEE, em 2004 começou em Angola um processo de integração escolar, apenas com 4 escolas, e em 2015 eram mais de 800 estabelecimentos, em que alunos com NEE aprendem em turmas regulares. A dificuldade, causada pela crise, na aquisição de materiais escolares e a formação de professores são obstáculos a uma maior realização da inclusão (Pimentel, 2015).

Apesar do processo de inclusão estar a procurar fazer o seu trajeto, em todo o país, a realidade da sua evolução é diferente em cada uma das 18 províncias angolanas.

\section{Inclusão escolar: o desafio do momento}

No século XXI, promover a inclusão de todos os cidadãos continua a ser um desafio às sociedades. Segundo Guerreiro (2011, p. 17):

a deficiência, que se opõe à eficiência, filosofia/doutrina desumanizante que nega a eficiência às pessoas marcadas com um qualquer estigma, fundada essencialmente em crenças, mitos e preconceitos, é um atributo/ rótulo que continua a condicionar ou a impedir pessoas na sua participação familiar e social, como legítimo e indiscutível direito cívico e de cidadania. 
De acordo com a Carta para o Terceiro Milénio3, "deve ser objetivo de todos os Estados, no terceiro milénio, evoluírem para sociedades que protejam os direitos das pessoas com deficiência, garantindo-Ihes um maior poder e a sua inclusão em todos os aspetos da vida em sociedade" (Guerreiro, 2012, p.73). Neste contexto, há uma preponderante preocupação de inclusão escolar de crianças e jovens com deficiência, de modo a uma maior concretização da sua inclusão social.

Neste âmbito, houve uma evolução: a partir dos meados do século XX, o direito à diferença das crianças e jovens em situação de deficiência e a sua inclusão na família, na escola e na sociedade, tem vindo a fazer parte do discurso de experts e políticos, na área social e educativa (Sanches, 2011a), constituindo-se "como um valor maior da Constituição e como o Direito dos Direitos", como afirmou o Presidente da República Portuguesa no V Congresso Internacional da Pró - Inclusão "Educação, Inclusão e Inovação" (2017).

Os países têm sido instados, por organismos internacionais (UNESCO, União Europeia, entre outros) a dar prioridade, nas suas políticas, à Educação para Todos, numa perspetiva inclusiva, através da assinatura de compromissos e declarações que os comprometem a nível internacional e nacional.

A vontade de uma Educação para Todos foi evidenciada na Conferência Mundial de Educação para Todos em 1990, que resultou no compromisso de garantir esse direito, independentemente das diferenças individuais. Em 1993, surgiram as "Normas das Nações Unidas sobre a Igualdade de Oportunidades para as Pessoas com Deficiência, as quais exortam os Estados a assegurar que a educação das pessoas com deficiência faça parte integrante do sistema educativo" (UNESCO,1994, p. vii). E que "as crianças e jovens com necessidades educativas especiais devem ter acesso às escolas regulares, que a elas se devem adequar através duma pedagogia centrada na criança, capaz de ir ao encontro destas necessidades" (p. viii).

Guerreiro (2012, p.77) enfatiza que "sendo o conhecimento um bem público e, nessa medida acessível a todos e partilhado por todos, ninguém deve achar-se excluído dele".

Com a referida Conferência Mundial de Educação para todos e com a Declaração de Salamanca de Princípios, Política e Prática para as Necessidades Educativas Especiais "entrámos na era da inclusão" (Guerreiro, 2011, p. 41).

De acordo com a Declaração de Salamanca, as escolas regulares são os "os meios mais capazes para combater as atitudes discriminatórias, criando comunidades abertas e solidárias." (UNESCO,1994, p. vii).

Conforme referido no relatório do International Disability and Development Consortium (IDDC) a exclusão de crianças com deficiências é um grande obstáculo para os Objectivos de Desenvolvimento Sustentável (ODS), que visam assegurar a educação inclusiva e equitativa para todos, em 2030 (Tabary, 2016). É objetivo do IDDC promover 
o desenvolvimento inclusivo, focando especialmente o pleno e efetivo exercício dos direitos humanos pelas pessoas em situação de deficiência que vivem em comunidades economicamente pobres, em países de renda média e baixa.

Os países, cada um à sua maneira, têm vindo a desenvolver políticas/legislação, tendo como enfoque a inclusão, embora muitas vezes a operacionalização das mesmas configure mais a exclusão que a inclusão. A inclusão é uma caminhada que ainda mal começou e que evoluirá, num sentido ou no outro, de acordo com o sentido do nosso investimento (Sanches, 2011b). Sabe-se que o investimento humano e financeiro com a inclusão é muito grande, mas será ainda maior o desinvestimento. Investir bem nas pessoas é sempre um bom princípio.

A escola é o lugar privilegiado para que a inclusão plena (acesso, permanência, participação, desenvolvimento e sucesso) se operacionalize, dando a cada um o direito de viver e aprender com todos e cada um, respeitando e fazendo-se respeitar, de acordo com a igualdade e a diferença que Ihes assiste. As crianças e jovens com NEE obrigaram a "olhar" e a inquietar sobre a necessidade da igualdade de oportunidades e da oferta da eficácia das nossas escolas, sendo cada vez mais difícil (embora ainda possível, em alguns casos) excluir crianças e jovens da escola que é de todos e para todos.

Paulo (2017) refere que as crianças com NEE têm o direito4:

à frequência de escolas regulares de educação e ensino, que, numa perspectiva de escola para todos, procuram dar respostas diferenciadas às necessidades de cada um. A regra é a inclusão no ensino regular, assumindo a saída para escolas especiais um carácter de excepção, que assenta no pressuposto de que foram esgotados todos os meios para manter o aluno no ambiente escolar normal.

Para que as escolas sejam realmente inclusivas, quando confrontadas com alunos com necessidades educativas especiais, recomendamos, na peugada de Carita e Carvalho (2016, p.124):

- planeamento da ação psicopedagógica, no domínio do desenvolvimento da capacitação social dos alunos (...);

- trabalho continuado de sensibilização de todos os alunos às diferenças e de formação cidadã no campo dos direitos humanos, com base em estratégias cooperativas de aprendizagem e de lazer;

- reforço contínuo da formação de todos os envolvidos no processo educativo (...).

Se a segunda metade do século XX foi marcado pela entrada das crianças e jovens em situação de deficiência na escola, que o princípio do século XXI seja lembrado como o tempo da inclusão plena com 
- acesso, permanência, participação, desenvolvimento e sucesso de todos e de cada um (Costa \& Sanches, 2016),

- fim da discriminação,

- igualdade de oportunidades, de respeito por si e pelos outros, como pessoa humana, independentemente da sua condição e

- "valor maior e o Direito dos Direitos", como disse o Presidente da República Portuguesa, Marcelo Rebelo de Sousa, em conferência do V Congresso Internacional da Pró - Inclusão "Educação, Inclusão e Inovação" (julho, 2017).

\section{Os procedimentos e resultados da pesquisa}

Para dar cumprimento ao nosso objetivo: compreender a realidade da Educação Especial em Angola, especificando o caso do Namibe, centrámo-nos na pesquisa e análise de documentos disponibilizados e da legislação existente sobre esta temática. Complementou-se a informação com uma entrevista semiestruturada à diretora pedagógica da Escola Especial do Namibe. Toda a informação selecionada foi analisada e agregada em unidades temáticas que nos ajudam a compreender esta realidade. São elas: (i) Crianças em situação de deficiência, em Angola: o que dizem as estatísticas; (ii) Evolução da Educação Especial em Angola; (iii) O caso do Namibe.

\subsection{Crianças em situação de deficiência, em Angola: o que dizem as estatísticas}

Segundo o Governo de Unidade e Reconciliação Nacional (2000), em 1996, havia cerca de 85.000 crianças com algum tipo de deficiência, representando 1,3\% deste estrato populacional, com níveis mais baixos nas áreas urbanas. Segundo a mesma fonte "a paralisia das pernas é a deficiência mais comum, responsável por cerca de 34\% de todas as deficiências nas crianças"5. Nessa época, em 1996, a aceitação das pessoas com deficiência era feita com algumas reservas.

Em Angola, referindo-se a dados de 2011, "o maior índice de crianças com deficiência física encontra-se na região centro e sul do país, onde o conflito armado foi mais intenso"6 e o preconceito contra estas crianças é bem real.

Em 2012 foram identificadas 28.456 crianças e jovens (entre os zero e 17 anos), com deficiência, que procuraram assistência social nas diferentes instituições governamentais. Há uma estimativa que aponta em 2\%, a existência de crianças com NEE, no total da população. No entanto, este valor fica abaixo da realidade pois as famílias tendem a ocultar esta situação, devido ao estigma social e cultural de que são vítimas (Lusa, 2013). Em 2017, continua a não haver uma estatística mais realista deste grupo populacional. 


\subsection{Evolução da Educação Especial em Angola}

Angola é uma ex-colónia portuguesa e de acordo com o Instituto Nacional para a Educação Especial (INEE) (2008), "o sistema educativo colonial não contemplava o atendimento escolar das pessoas com deficiência” (p.23). Foi a nível privado, em 1972 (ainda no sistema colonial), que começou o ensino direcionado especificamente às crianças com necessidades especiais em território angolano, iniciando com 10 crianças cegas.

Foi no período pós-independência, em 1979, que foi implementada a Educação Especial $^{7}$ e posteriormente, em 1980, criado o Departamento Nacional para a Educação Especial ${ }^{8}$. Os espaços concebidos para esse fim eram separados dos demais, e os primeiros beneficiários foram as crianças com deficiência visual e auditiva e, só mais tarde, as crianças com deficiência mental.

Surge, como marco de viragem para esta população específica, a participação de Angola, em 1994, na Conferência Mundial sobre as Necessidades Educativas Especiais (NEE), em Espanha e a consequente assinatura da Declaração de Salamanca. Desta surgiu "a implementação do Projecto 534/Ang/10 sobre 'Promoção de Oportunidades Educativas para a Reabilitação das Crianças Vulneráveis?' que permitiu a integração de crianças com necessidades educativas especiais, nas escolas do ensino regular, em salas especiais e integradas." (INEE, 2008, p.24).

Em 1995, foi criada a Direção nacional para a Educação Especial ${ }^{9}$. Contudo, esse trabalho educativo estava delimitado às zonas não afetadas pela guerra civil. A Educação Especial era referida, em 1996, do seguinte modo: "em Angola destina-se aos alunos com necessidades educativas especiais, para superar os seus problemas de aprendizagem, prevenir o surgimento de mais casos, corrigir e compensar os defeitos $^{10}$ (itálico adicionado) e prepará-los para a vida." (República de Angola,1996, p.20).

Nesse ano (1996) a educação especial era limitada e abrangia um número reduzido. As condições de guerra não permitiam o desenvolvimento deste tipo de educação, apesar do grande número de crianças que dele necessitavam. Além disso, eram indicadas instituições específicas para este grupo de crianças e havia falta de infraestruturas, de recursos humanos devidamente preparados e recursos financeiros e materiais para efetivá-las. Esta separação de alunos, afastando-os dos demais, criava segregação.

De acordo com Guerreiro (2012) "os fatores que mais pesam na cultura do segregacionismo são essencialmente de natureza exógena" (p. 73). Devido a variadas dificuldades muitas crianças com NEE ficam fora do sistema educativo, permanecendo em casa ou abandonadas nas ruas.

Um Guia de Apoio ao Professor do Ensino Gerall1 de 1996, sobre integração das crianças com NEE, alerta que: 
Não devemos continuar a criar 'micromundos' entre pessoas, segregando-as por grupos e em instituições específicas, salvo aquelas que pela gravidade do seu defeito [itálico adicionado] (deficiências profundas) têm de ser atendidas em instituições especiais. Isto requer uma mudança significativa na atitude dos professores, dos alunos e da sociedade em geral para em primeira instância 'aceitar' e 'restituir' os alunos portadores de necessidades educativas especiais à escola regular. Em segunda instância preparar-se com recursos e conhecimentos específicos para adaptar todo sistema educativo a esta realidade. (p.22).

O Instituto Nacional para a Educação Especial (2009) esclareceu que houve alterações a nível mundial no atendimento aos alunos com NEE, pois que anteriormente a pedagogia concentrava-se no "defeito" do aluno, como visto acima, do qual se fazia um diagnóstico psicopedagógico fechado e final e agora centraliza-se nas potencialidades e fortalezas deste, com um diagnóstico aberto e não-definitivo. Este novo diagnóstico tem três itens:

- Diagnóstico-escolar/inicial/professor - em que o professor faz a caracterização psicopedagógica do aluno;

- Diagnóstico especializado - realizado pelo especialista, a partir da informação do professor; e,

- Atendimento educativo especializado - apoio complementar ou suplementar realizado após a inclusão do aluno.

Para o atendimento escolar das crianças com Necessidades Educativas Especiais (NEE) foram alocadas responsabilidades às entidades envolventes, distribuídas conforme Tabela 1.

A paz, alcançada em 2002, permite o alargamento nacional da Educação Especial. Nesse ano foram matriculados 7.406 alunos, mais 3.000 do que no ano anterior e em 2007 eram 16.393. Nesse mesmo ano, havia 3.182 professores alvos de formação específica para esta população e implementados vários projetos e instrumentos de orientação. Contudo, em 2008, ainda estava longe de atingir os 50\% da população objetivada (INEE, 2008).

Desde 2011, o objetivo geral da Educação Especial é "atender, orientar, acompanhar, formar e apoiar a inclusão socioeducativa e familiar das crianças, jovens e adultos com necessidades educativas especiais." (Decreto Presidencial no 20/11, artigo $5^{\circ}$, p. 299). Nesse ano mais de 22.000 alunos com NEE estavam inseridos nas escolas (Wedel, 2011). 
Tabela 1 - Responsabilidades institucionais

\begin{tabular}{|c|c|c|}
\hline MED/INEE & $\begin{array}{c}\text { DPE/SECÇÃO PROVINCIAL } \\
\text { EE/REPARTIÇÃO MUNICIPAL } \\
\text { DA EDUCAÇẪO }\end{array}$ & ESCOLAS \\
\hline $\begin{array}{l}\text { Apoio técnico metodológico } \\
\text { às repartições e escolas }\end{array}$ & $\begin{array}{l}\text { Abertura de salas para o } \\
\text { Atendimento Educacional } \\
\text { Especializado (AEE) }\end{array}$ & $\begin{array}{c}\text { Envolvimento direto das } \\
\text { direções das escolas no } \\
\text { processo da educação } \\
\text { inclusiva }\end{array}$ \\
\hline $\begin{array}{c}\text { Formação e capacitação de } \\
\text { técnicos e professores }\end{array}$ & $\begin{array}{l}\text { Criação de brinquedotecas } \\
\text { no Centro de Diagnóstico e } \\
\text { Orientação (CDO) }\end{array}$ & $\begin{array}{c}\text { Promover palestras de } \\
\text { informação e sensibilização } \\
\text { sobre educação inclusiva } \\
\text { aos trabalhadores }\end{array}$ \\
\hline $\begin{array}{c}\text { Promover campanhas de } \\
\text { informação e sensibilização } \\
\text { sobre educação inclusiva } \\
\text { nas escolas }\end{array}$ & $\begin{array}{l}\text { Apetrechamento das salas } \\
\text { de Atendimento Educacional } \\
\text { Especializado }\end{array}$ & $\begin{array}{c}\text { Garantir a matrícula de todos } \\
\text { os alunos }\end{array}$ \\
\hline $\begin{array}{l}\text { Apetrechamento das salas } \\
\text { de Atendimento Educacional } \\
\text { Especializado }\end{array}$ & $\begin{array}{l}\text { Solicitação de formação de } \\
\text { professores }\end{array}$ & $\begin{array}{l}\text { Solicitar a presença dos } \\
\text { técnicos do Centro de } \\
\text { Diagnóstico e Orientação, } \\
\text { sempre que houver suspeita } \\
\text { de alunos com NEE }\end{array}$ \\
\hline & $\begin{array}{l}\text { Promover palestras de } \\
\text { informação e sensibilização } \\
\text { sobre educação inclusiva }\end{array}$ & $\begin{array}{c}\text { Envolver os pais e } \\
\text { Encarregados de Educação } \\
\text { no processo de ensino e } \\
\text { aprendizagem }\end{array}$ \\
\hline & $\begin{array}{c}\text { Garantir a presença } \\
\text { de técnicos nos } \\
\text { estabelecimentos de ensino } \\
\text { para o acompanhamento dos } \\
\text { alunos e apoio às Direções e } \\
\text { professores }\end{array}$ & ---- \\
\hline
\end{tabular}

Nota: MED = Ministério da Educação; DPE = Direção Provincial da Educação. Fonte: Instituto Nacional para a Educação Especial (INEE, 2009)

A um ritmo aquém das expetativas o crescimento vai surgindo, pois, em 2013 eram 23.193 alunos com NEE em 14 Escolas Especiais (Lusa, 2013). E em 2015, o director do INEE ${ }^{12}$, afirmou haver, a nível nacional, mais de 30 mil alunos com NEE e 17 Escolas Especiais. Admitiu como fatores contraproducentes a escassez de professores para essa área e de recursos didáticos nesse sector.

Em 2016, segundo o MED ${ }^{13}$, o número de Escolas Especiais passa para 20, e, nesse mesmo ano é apoiada e reforçada a universalidade do ensino, na Lei 17/16 de 07 de Outubro: 
O Sistema de Educação tem carácter universal, pelo que, todos os indivíduos têm iguais direitos no acesso, na frequência e no sucesso nos diversos níveis de ensino, desde que sejam observados os critérios de cada Subsistema de Ensino, assegurando a inclusão social, a igualdade de oportunidades e a equidade bem como a proibição de qualquer forma de discriminação. (Artigo 8.\%).

A modalidade do Ensino Especial aparece na supracitada Lei (de forma detalhada na Seção II), afirmando que esta visa a integração socioeducativa dos seus alunos (Art. ${ }^{\circ} .81^{\circ}$ ) e os três primeiros objetivos específicos, dos sete apresentados (Art. ${ }^{\circ} .82^{\circ}$ ), são:

a. Assegurar aos indivíduos com necessidades educativas especiais o alcance dos objectivos educativos dos diferentes subsistemas de ensino;

b. Desenvolver as potencialidades físicas e intelectuais, reduzindo as limitações provocadas pelas deficiências ou transtornos;

c. Apoiar a inserção familiar, escolar e social dos indivíduos com necessidades educativas especiais, ajudando na aquisição de estabilidade emocional e social, bem como a auto-estima e a auto-confiança. (p. 33).

Para a concretização dos objetivos educacionais nacionais pretende-se que a educação seja inclusiva e que a escola seja equitativa para todos, o que é um grande desafio.

\subsection{O caso do Namibe}

A província do Namibe situa-se no litoral sul de Angola. Nesta, o cuidado institucional das crianças com deficiência começa no final do século $X X$, no ano letivo 1994/1995, na Escola 4 de Fevereiro ${ }^{14}$ no Município de Moçâmedes, com uma turma anexa constituída por apenas quatro alunos e três professores, que lecionaram a classe de iniciação e a $1^{\text {a }}$ classe.

O reconhecimento das necessidades de expansão do local e a evolução do ensino para este tipo de crianças fez surgir a Escola Primária e Secundária do I Ciclo № 40 de Namibe do Ensino Especial, única na Província com essa finalidade, no Município de Moçamedes, no centro da cidade ${ }^{15}$. Esta foi criada pelo Decreto Executivo no 67, de 20 Outubro de 2004, mas só entrou em funcionamento ${ }^{16}$ no simbólico dia 4 de Fevereiro ${ }^{17}$, no ano de 2005.

O número de alunos foi crescendo, entre 2010 e 2012 rondavam os 550, mas com o início do processo de inclusão escolar em 2011, esta escola sentiu um decréscimo no ritmo de crescimento do número de alunos. Isto foi causado pela implementação dos serviços de Atendimento Educacional Especializado, retirando alunos do centro 
da cidade para as zonas suburbanas, assim em 2013 eram 460 e nos anos posteriormente houve oscilações. Para uma melhor visão da evolução entre 2015 e 2016, na província e depois no município, apresentam-se as Tabelas 2 e 3:

Tabela 2 - Alunos com NEE matriculados em 2015 e 2016

\begin{tabular}{|c|c|c|c|c|c|c|}
\hline $\begin{array}{c}\text { No de alunos com NEE } \\
\text { matriculados }\end{array}$ & \multicolumn{3}{|c|}{$\begin{array}{c}\text { Província } \\
\text { Namibe }\end{array}$} & \multicolumn{3}{c|}{$\begin{array}{c}\text { Município } \\
\text { Moçâmedes }\end{array}$} \\
\hline & MF & F & M & MF & F & M \\
\hline ANO 2015 & 1998 & 1073 & 925 & 1867 & 1021 & 846 \\
\hline ANO 2016 & 2406 & 1192 & 1214 & 2112 & 1062 & 1086 \\
\hline
\end{tabular}

Nota: $M=$ Masculino; F= Feminino.

Fonte: Departamento de Estudos, Planeamento e Estatística da Direcção Provincial da Educação, Ciência e Tecnologia do Namibe, em 24/02/2017.

Observando a Tabela constata-se uma prevalência feminina em 2015, mas em 2016, a nível provincial, esta altera-se. É de salientar que os alunos com deficiências motoras e os alunos com deficiências ligeiras são incluídos nas escolas regulares, seguindo a prática da inserção social. Só os considerados com deficiência moderada e/ou alta é que são matriculados na Escola Primária e Secundária do I Ciclo Nº 40-N de Namibe (Escola Especial). Nessa, no mesmo período, os números são conforme a Tabela 3:

Tabela 3 - Alunos com NEE matriculados na Escola Especial em 2015 e 2016

\begin{tabular}{|c|c|c|c|c|c|}
\hline $\begin{array}{c}\text { No de alunos com NEE matriculados } \\
\text { na Escola Especial }\end{array}$ & \multicolumn{3}{c|}{$\begin{array}{c}\text { Província } \\
\text { Namibe }\end{array}$} & \multicolumn{2}{c|}{$\begin{array}{c}\text { Município } \\
\text { Moçâmedes }\end{array}$} \\
\hline & MF & F & M & MF & F \\
\hline ANO 2015 & 360 & 165 & 195 & 360 & 165 \\
\hline ANO 2016 & 404 & 176 & 228 & 404 & 176 \\
\hline
\end{tabular}

Nota: $M=$ Masculino; F= Feminino.

Havendo só uma Escola Especial, os números são os mesmos na província e no município.

Fonte: Departamento de Estudos, Planeamento e Estatística da Direcção Provincial da Educação, Ciência e Tecnologia do Namibe, em 24/02/2017.

Nesta instituição a predominância estudantil nesse período (2015-2016) foi masculina e continua sendo desse modo, pois no ano lectivo ${ }^{18}$ de 2017 , tem 432 alunos ${ }^{19}$ dentre os quais apenas 192 são do sexo feminino. Uma das razões que pode ser apontada para esta situação é de ordem cultural: entregar as tarefas domésticas às meninas e a crença de que os meninos têm mais oportunidades de trabalho remunerado. 
Os 357 alunos com NEE estão divididos em 8 turmas definitivas ${ }^{20}$ e 3 adaptadas (construídas conforme as necessidades que vão surgindo ao longo do ano letivo). A deficiência que aparece em maior número é a auditiva seguida da intelectual; o Síndrome de Down aparece em quarto lugar e depois dele a deficiência visual (baixa ou total) ${ }^{21}$. As turmas da Educação Especial têm 20 tempos letivos (Artigo $15^{\circ}$ do Decreto presidencial $\left.n^{\circ} 16 / 11\right)$.

A instituição, Escola Primária e Secundária do I Ciclo № 40 de Namibe (Escola Especial), teve um Projecto Educativo ${ }^{22}$ para 2014 e 2015, feito de forma participada, considerado o documento que consagra a orientação desta ${ }^{23}$. No Projeto Educativo afirma-se que o objetivo principal da instituição é "formar futuro do amanhã" (p.15). A escola tem como parceira a Associação de Pais e Encarregados de Educação na resolução dos problemas que surgem (pedagógicos, metodológicos e administrativos). Os problemas identificados nessa altura foram os de aprendizagem; desempenho profissional; participação de pais e de encarregados de educação; domínio da língua gestual angolana, da escrita em Braille e da metodologia para surdos e alunos com deficiência intelectual; entendimento sobre a funcionalidade do Atendimento Educativo Especializado (AEE); e, a assiduidade e pontualidade dos alunos. No mesmo Projeto Educativo, adianta-se que para a redução dos problemas foram colocados objetivos, como por exemplo "diminuir a falta de assiduidade; aumentar a qualidade do processo de ensino-aprendizagem." (p. 9). Para este último foram assinaladas atividades como: encontros metodológicos e trocas de experiências entre professores e treinamento local sobre as NEE, entre outras. Com o objetivo de aumentar a participação de pais e encarregados de educação foram realizadas reuniões entre estes e a escola ou com os professores. Para, além disso, foram efetuadas formações de orientação para os pais e encarregados sobre como apoiar o educando com NEE, de modo a melhorar a capacidade de aprendizagem deste.

Para melhorar a compreensão da comunidade sobre as NEE, a instituição procura realizar campanhas de sensibilização e informação. Nesse âmbito, a diretora pedagógica, esclareceu numa entrevista ${ }^{24}$, que em 2010 e 2011 fez-se uma campanha provincial: porta a porta foram saber se havia crianças com necessidades especiais trancadas em casa e levaram alguns encarregados de educação destas a conhecer a escola e a encorajá-los a aceitarem a frequência do educando.

Estando o país em crise, desde o final de 2014, a instituição passa por diversas dificuldades devido aos escassos recursos financeiros face às necessidades. A diretora pedagógica, na mesma entrevista, frisa a debilidade na formação do pessoal que ficou interrompida por falta de financiamento; a falta de salas e material próprio para as várias deficiências; e, os poucos aparelhos específicos estão danificados ou com falta de manutenção. Uma necessidade gritante é a de especialistas na área de apoio ao ensino (ex.: pediatra, psicólogo, etc.). Menciona também a necessidade de uma maior 
segurança nas cercas da escola e a falta de meio de transporte institucional, que limita o apoio externo a professores e alunos nos lugares mais longínquos.

Algumas dificuldades nos recursos materiais na instituição são colmatadas pelo engenho, por exemplo: para a prática da aprendizagem do sistema Braille, e do seu sinal fundamental (conjunto de 6 pontos), utiliza-se uma caixa vazia de meia dúzia de ovos; os manuais/guias para os formadores são fotocopiados e distribuídos; e, uma sirene, do tipo dos bombeiros, assinala o início e fim dos tempos letivos e intervalos.

A dificuldade de sair da capital provincial para dar resposta às necessidades de outros municípios, por falta de transporte institucional, é colmatada, por exemplo, com a deslocação de professores desses locais, que vão quinzenalmente a Moçâmedes, aos sábados, para adquirirem formação, com vista à inclusão das crianças com NEE, que vão aparecendo nas suas escolas.

A diretora pedagógica ${ }^{25}$ realça, como obstáculo para uma maior inclusão social, a falta de "Salas de Recurso" na província, onde se pode profissionalizar os alunos (ex: aulas teórico-práticas de culinária, pastelaria, serralharia, etc.) e de parcerias, para que os que completam 18 anos pudessem ser inseridos no mercado de trabalho. A realidade é que os que estão nessa situação ficam em casa ou continuam a vir à escola como ocupação e assim há alunos já com 22 anos, sem esperança profissional. Dos adultos, que ali foram alunos, são raros os que estão no mercado do trabalho, estes trabalham por conta própria, nomeadamente um pescador, um serralheiro, um cantor e um fotógrafo. Existem vários que andam deambulando pela rua como vendedores ambulantes, em busca de algum sustento.

\section{Conclusões}

Num país pós-conflito, como é Angola, a Escola Especial e a inclusão escolar de crianças com NEE constituem um caminho cheio de desafios que a presente crise económica não ajuda, ou melhor, dificulta o progresso almejado neste setor.

A política nacional de Educação Especial perspetiva uma escolaridade cada vez mais inclusiva, com vista à integração social, evitando a exclusão das crianças com NEE e favorecendo desse modo o desenvolvimento das competências de cada criança, concedendo oportunidades para que possa exercê-las dentro da escola, família e sociedade.

Para aumentar a probabilidade de uma integração social duradoira, é necessário trabalhar para sensibilizar as populações, com o propósito de melhorar a imagem que a sociedade angolana tem das pessoas com deficiência; encontrar mecanismos para a participação social de cada indivíduo, para que possa ser independente e um cidadão produtivo, com base nas suas potencialidades. É gritante a necessidade de 
investimento, nesta modalidade educativa, que permita a atualização e acréscimo de recursos e de profissionais formados na área.

É urgente um maior contributo para o desenvolvimento sustentável deste país, que procura criar uma sociedade inclusiva, num mundo cada vez mais globalizado, onde a diferença tem de ser vista como uma oportunidade de agir e não um obstáculo e onde o cumprimento pleno dos Direitos da Criança e das Pessoas com Deficiência é uma oportunidade para a reconstrução nacional.

\section{Notas}

1 A Convenção foi aprovada pela Comissão Permanente da Assembleia do Povo na XIVa sessão extraordinária da Il legislatura, realizada a 21 de Setembro de 1990.

2 Contemplada na Secção VIII da Lei no 13/01, de 31 de Dezembro (Lei de Bases do Sistema de Educação). Definida como "a modalidade de ensino transversal que disponibiliza recursos específicos para o atendimento aos alunos com necessidades educativas especiais " (Decreto Presidencial $n^{\circ} 20 / 11$, artigo $2^{\circ}$, p. 298).

3 Aprovada a 09/09/1999, em Londres, pela Assembleia Geral da Rehabilitation Integration.

4 Powerpoint da Escola Primária e Secundária n $40-\mathrm{N}$ do $1^{\circ}$ Ciclo do Ensino Especial «Namibe».

5 "Os outros principais tipos [...] são deficiências auditivas e da fala (16\%), perna mutilada (9\%), doença mental $(7 \%)$, cegueira (6\%) e paralisia do braço (6\%)." Sendo a causa, doença (42\%) ou congénita (29\%), guerra (12\%), acidentes (8\%) e minas (3\%)" (p.17). É de salientar que mesmo após a paz as minas continuam a matar e a incapacitar pessoas, especialmente nas zonas rurais, porque o processo da sua desativação é moroso e dispendioso.

${ }^{6}$ Referiu o coordenador da ONG Promoção e Proteção dos Direitos da Criança em Angola, Mbuta Pascoal (Wedel, 2011).

7 Pela Circular n 56 de 19 de outubro, por despacho e orientação do então Ministro Ambrósio Lukoki.

8 Artigo $17^{\circ}$ do Decreto n 40/80 de 14 de maio - Estatuto Orgânico do Ministério da Educação (MED).

9 Pelo Decreto-lei no 13/95 de 27 de outubro - artigo $18^{\circ}$ do Estatuto Orgânico do MED.

${ }^{10}$ Atualmente o foco não é já o "defeito" do aluno, mas são as potencialidades e fortalezas deste; este assunto é mencionado posteriormente neste mesmo artigo.

${ }^{11}$ República de Angola (1996). Integração de crianças com necessidades educativas especiais no ensino geral: O Guia de Apoio ao Professor do Ensino Geral.

12 Jorge Pedro, numa entrevista ao jornal Nova Gazeta, de 7 de maio de 2015, pp.18,19. Artigo de Pimentel, E., intitulado "Ensino Especial ainda com dificuldades".

${ }^{13}$ Fonte: http://www.angop.ao/angola/pt_pt/noticias/educacao/2016/5/22/Angola-Ensino-especial-controla-cerca-mil-alunos-2016,8a119d90-3973-4498-9fab-e7308e13c5ef.html.

${ }^{14} \mathrm{O}$ dia 4 de fevereiro de 1961 foi um marco histórico para Angola, pois marca o início da luta armada de libertação nacional. Essa data é atribuída a muitos espaços, é feriado e acontecem muitos eventos importantes evocando o seu simbolismo.

${ }^{15}$ Devido à sua localização, a maior parte dos alunos gastam diariamente algumas horas para chegar à Escola.

${ }^{16}$ Durante o período diurno a escola leciona crianças com Necessidades Educativas Especiais (NEE), mas no período noturno funciona para alunos sem necessidades diagnosticadas.

17 Ver nota de rodapé 9.

${ }^{18} \mathrm{O}$ ano letivo corresponde ao ano civil, indo de meados/fins de fevereiro até 23 de dezembro. O calendário escolar para cada subsistema é elaborado pelo Ministério da Educação.

1975 são alunos do período noturno. 
${ }^{20}$ As salas foram constituídas para 21 alunos por turma, no entanto esse número varia dependendo da deficiência dos alunos que vão surgindo.

${ }^{21}$ Deficiência auditiva =154 alunos; intelectual=146; Síndrome de Down = 39; deficiência visual =15; e autistas $=3$. Fonte: Direção da Escola.

22 Os projectos educativos têm por base a Lei de Bases do Sistema Educativo (Lei nº13/01 de 31 de Dezembro).

${ }^{23}$ Este Projeto da Escola norteou também a instituição no ano de 2016 e espera a sua avaliação e atualização em 2017.

${ }^{24}$ Entrevista a 02-03-2017, na instituição, em resposta sobre como funcionam as campanhas de sensibilização à comunidade para reduzir a exclusão social das crianças com NEE.

${ }^{25}$ Entrevista a 02-03-2017, na instituição, quando questionada sobre as dificuldades em 2017.

\section{Referências Bibliográficas}

Carita, A. \& Carvalho, C. (2016). Qualidade inclusiva da escola. Representações da comunidade educativa de uma escola frequentada por um aluno com Síndroma de Asperger. Revista Lusófona de Educação, 34, 107-126.

[Disponível em: http://revistas.ulusofona.pt/index.php/rleducacao/article/view/5819, consultado em 30/05/2016]

Costa, G. \& Sanches, I. (2016). Um olhar sobre a inclusão educativa: conceções dos professores do ensino secundário. Revista Lusófona de Educação, 34, 161-179.

[Disponível em: http://revistas.ulusofona.pt/index.php/rleducacao/article/view/5822, consultado em 30/05/2016]

Guerreiro, A. D. (2012). Comunicação e cultura inclusivas. Lisboa: Edições Universitárias Lusófonas.

Guerreiro, A. D. (2011). Comunicar e interagir: um novo paradigma para o direito à participação social das pessoas com deficiência. Lisboa: Edições Universitárias Lusófonas.

Instituto Nacional para a Educação Especial [INEE]. (2009). Orientações Gerais. Luanda: INEE.

Instituto Nacional para a Educação Especial [INEE]. (2008). I Encontro metodológico sobre a Educação Especial. Luanda: INEE.

Jundo, E. de C. (2014). Projecto Educativo 2014-2015. Escola Primária e Secundária nº 40-N do $1^{\circ}$ Ciclo do Ensino Especial «Namibe».

Pimentel, E. (2015). Ensino Especial ainda com dificuldades. Nova Gazeta, 7,18-19.

Paulo, S. (2017). N.E.E./ inclusão. Powerpoint da Escola Primária e Secundária n $40-\mathrm{N}$ do $1^{\circ}$ Ciclo do Ensino Especial «Namibe».

Lusa (2013). Governo angolano reconhece que legislação sobre pessoas com deficiência não contempla crianças. Luanda: Lusa. [Disponível em http://noticias.sapo.ao/lusa/artigo/16207536. html, consultado em 30/05/2013].

Sanches, I. (2011a). Em busca de Indicadores de Educação Inclusiva. A "voz" dos professores de apoio sobre o que pensam, o que fazem e o que gostariam de fazer. Lisboa: Edições Universitárias Lusófonas. 
Sanches, I. (2011b). Do 'aprender para fazer' ao 'aprender fazendo': as práticas de Educação inclusiva, na escola. Revista Lusófona de Educação, 19,157-163. [Disponível em:

http://revistas.ulusofona.pt/index.php/rleducacao/article/view/2846, consultado em 15/02/2016] .

Sousa, M. R. de (2017). Conferência proferida no V Congresso Internacional da Pró - Inclusão "Educação, Inclusão e Inovação". Escola Superior de Comunicação Social, 7 de julho.

Tabary, Z. (2016). Metade das crianças com deficiência não vai à escola. Reuters, 17/10/2016. [Disponível em http://www.redeangola.info/metade-das-criancas-com-deficiencia-nao-vai-aescola, consultado em 23/02/2016].

UNESCO (1994). Declaração de Salamanca e enquadramento da acção na área das necessidades educativas especiais - Conferência mundial sobre necessidades educativas especiais: acesso e qualidade. Salamanca, Espanha. [Disponível em http://redeinclusao.pt/media/fl_9.pdf., consultado em 27/02/2016].

Webel, C. (2011). Inserção social de crianças deficientes em Angola. DW Made for minds. 21/03/2011. [Disponível em: http://www.dw.com/pt-002/inser\%C3\%A7\%C3\%A3o-social-de-crian\%C3\%A7asdeficientes-em-angola/a-14927569, consultado em 22/02/2016].

\section{Textos Legislativos}

Lei no 17/16 de 07 de outubro. Apresenta a nova Lei de Bases do Sistema de Educação.

Lei 13/01, de 31 de dezembro, Lei de Bases do Sistema de Educação. Diário da República. Luanda.

Decreto Presidencial n 16/11 de 11 de Janeiro - Diário da República, I Série - № 6 - Aprova o Estatuto do Subsistema do Ensino Geral.

Decreto Presidencial n 20/11 de 18 de Janeiro - Diário da República, I Série - №11 - Aprova o estatuto da Modalidade de Educação Especial.

Governo de Unidade e Reconciliação Nacional. (2000). Relatório de seguimento das metas da Cimeira Mundial pela Infância. Luanda: Autores.

República de Angola (1996). Integração de crianças com necessidades educativas especiais no ensino geral: Guia de apoio ao professor do ensino geral. Luanda: autores. 
Patatas \& Sanches: Desafios da educação especial infantil em Angola

Teresa Almeida Patatas

Doutora em Educação pela Universidade Lusófona de Humanidades

e Tecnologias de Lisboa. Professora na Escola Superior Politécnica do

Namibe, Angola. Investigadora do CeiED.

Email: teresapatatas.angola@gmail.com

Isabel Rodrigues Sanches

Professora Associada da ULHT; Doutora em Ciências da Educação (Société,

Handicap et Inclusion), pela Universidade Lumière de Lyon 2 - France; Coordenadora do Mestrado em Educação Especial; Investigadora Integrada

do CeiED.

Email: isabelrsanches@gmail.com

Correspondência Isabel Rodrigues Sanches

Universidade Lusófona Av. do Campo Grande, 376 1749-024 Lisboa

Data da submissão: Junho 2017

Data da avaliação: Setembro 2017

Data da publicação: Dezembro 2017 